A. Artigos escritos pelos estudantes brasileiros em Giessen, em língua alemã Die gemeinsame, aber differenzierte Verantwortlichkeit von Industriestaaten und Entwicklungslaendern für den Klimaschutz

Bernardo Becker Fontana.

Das Vorsorgeprinzip im Völkerrecht

Felipe Rocha dos Santos.

Die Gerechtigkeit zwischen Generationen:

Eine Untersuchung aus der Sicht des Umweltvölkerrechts und des Klimaregimes

Mangelhaftigkeit der Ware aufgrund öfentlich- rechtlicher Bestimmungen, die die Verwendbarkeit beschränken

Ioulia Dolganova...

Die Untersuchungs- und Rügeobliegenheit des Käufers nach Art. 38, 39 CISG

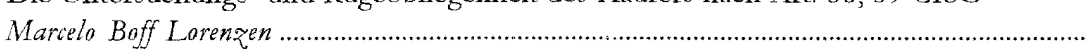

\section{B. Relato dos estudantes brasileiros sobre o programa UNIBRAL}

Bermardo Becker Fontana

Fernando Lusa Bordin

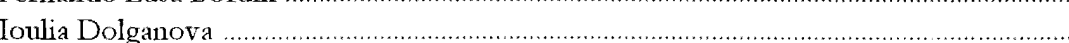

Marcelo Boff Lorenzen

\section{A experiência dos estudantes alemães na UFRGS}

Relato de Aeneas Nalbantis.

Relato de Micbel Lichtenberg

Relato de Marcus Balmert

\section{Os estudantes do Quebec na UFRGS}

Relato de Etienne Chennier.

Relato de Hughes Brisson.

\section{E. Artigos dos estudantes estrangeiros na UFRGS}

O comércio eletrônico e a proteçăo do consumidor no Canadá e no Quebec

Hughes Brisson

\section{Prof. Dr. Dr. h.c. Dieter Schwab}

Palestra realizada em comemoraýão ao Jubileu de 400 anos da Faculdade de Direito da Universidade Justus-Liebig, de Giessen, no dia 25 de Maio de 2007

Traducão de Bernardo Becker Fontana, Marcelo Boff Lorenzen, Ioulia Dolganova, Felipe Rocha dos Santos e Fernando Lusa Bordin. Reirião e versão final do texto de Lisiane Feiten Wingert $O d y$ que sempre urgem para fora da cidade, em direção às redondezas, procurando manter uma
Estimados convidados desta assembléia comemorativa

I.

O espírito flutua, por onde bem quer, contudo ele é preso ao tempo e ao espaço. Ele mostra-se como gênio da época, bem como gênio local, como genius loci, em cuja existência pelo menos os oradores costumam acreditar. E, assim, pensei que valeria a pena, por ocasião do grande Jubileu da Faculdade de Direito de Giessen, evocar o gênio local juridico de Giessen, para ver quais idéias jurídicas, quais paradigmas jurídicos de efeito permanente saídos deste lugar sopraram pelo mundo.

No que diz respeito ao lugar em si, descrições discordantes chegaram até nós, por meio das escritas de estudantes e professores: para uns - como para o mestre Laukhard -, Giessen parecia um lugarejo desprezível, opinião que apareceu pela segunda vez em uma carta de Rudolf Jhering, e a qual o autor, às vésperas de sua partida, intensifica para "ninho sujo (Drecknest) e miserável". Outros, pelo contrário, distinguem a cidade com o título honroso de "Atenas do Lahn". Para a maioria, Giessen nunca figurou entre as cidades universitárias mais belas, senão como uma cidade em que se pode estudar e pesquisar em sossego, gozar de uma vida idilica e vaguear pelos bosques para refrescar-se. "Tu sabes que me sinto bem aqui", escreve Jhering a Windscheid, "tenho uma posição tão agradánel.. . o motivo principal disso constitui-se daquilo que uma pequena cidade tem a oferecer - silêncio, vida interiorana, diversões ao ar liure etc. "Nesse idilio uniforme e silencioso, pode-se trabalhar, refletir, também passear vemos os Professores andando em Gleiberg e Schiffenberg, como também os estudantes, distância hostil, quando havia confronto com o reitor ou com o chanceler. A beleza de Giessen aumenta, por assim dizer, com a visão ao longe, e nosso espírito local só é compreensivel, se incluirmos as redondezas, os rios, os montes e os burgos.

Captar idéias jurídicas, as quais partiram de Giessen para o Mundo do Direito, considero uma tarefa encantadora, mas também ousada: em quatrocentos anos, os vivazes atores acadêmicos têm tantas novas idéias, que é impossível incluir todas em uma palestra. Desde a primeira geração de juristas que aqui estudou e lecionou até hoje, foram muitos os raios de genialidade que aqui caíram. Imperioso, assim, escolher somente alguns desses para representar o espírito local. 
Quero pedir compreensão para o fato de as idéias jurídicas dos séculos XVII e XVIII desempenharem apenas papel secundário em minha palestra. Deve ser por causa da falta de trabalhos anteriores que os juristas de Giessen daqueles tempos antigos não se destacaram como representantes de seus ramos. Em Direito do Estado houve alguns professores de Giessen, do lado do Imperador, que alcançaram distinção, como um certo Dietrich Reinking, que via no Sacro Império Romano-Germânico uma instituição divina para a eternidade, que duraria até o final dos tempos - uma idéia que não antecipou o futuro. No ano de 1694, fundou-se, ainda assim, uma cátedra para Direito Natural e Internacional, porém não na Faculdade de Direito, senão na de Teologia. A Faculdade de Economia, fundada em 1777 detém, com o fisiocrata Johann August Schlettwein, um representante pioneiro do jovem Direito Natural. Dentre os teólogos de Giessen, encontramos, de 1771 até 1775, o famoso e famigerado Carl Friedrich Bahrdt, o qual, devido a sua tradução da Bíblia, feita em Giessen, foi perseguido politicamente e acabou por tornar-se um defensor da liberdade religiosa e de imprensa na Alemanha.

$\mathrm{Na}$ Faculdade de Direito, não vimos tais gênios voltados ao futuro na ativa durante muito tempo, apesar de sempre serem representantes ativos do Direito Comum e do Direito do Estado, a cuja experiência jurídica (Spruchpraxis) freqüentemente se recorria.

No que diz respeito à segunda metade do século XVIII, inerece menção Ludwig Julius Friedrich Höpfner, o qual ganhou prestígio com um comentário ao Manual das Instituições (Institutionenlehrbuch) de Heineccius - naquele tempo, era comum basear as aulas em obras de outros cientistas e isso não era motivo de vergonha ou embaraço. Pelo contrário, Höpfner declarava-se partidário da prática, também na forma de um comentário impresso sobre o livro do outro. Höpfner também escreveu, em 1780, um livro relativamente avançado sobre o Direito Natural, o qual, por sua vez, baseou-se em um livro de outro autor, qual seja, Achenwall. Em outros círculos intelectuais, Höpfner ficou famoso, contudo, através da anedota que Goethe se permitiu com ele: como combinado corn dois amigos que conheciam Höpfner, o poeta de Wetzlar ia incógnito ao encontro do professor, passava-se por estudante de Direito e fazia todo tipo de brincadeiras com as palavras, até que, mais tarde, no restaurante. regado a vinho - neste meio-tempo os amigos já haviam chegado -, numa atmosfera descontraída, deixava cair a máscara. Tudo pode ser lido em „Dichtung und Wahrheit”.

\section{II.}

Se com Höpfner o genius loci já esfregava os olhos, ele somente acorda de fato em meados do século XIX, quando se deparou primeiramente com um homem, entre muitos, cujas idéias jurídicas já lotavam platéias. O já mencionado Rudolph Jhering, em 1852, contando com 34 anos de idade, aceitou uma nomeação para Giessen, depois de já ter tido cátedras na Basiléia, em Rostock e em Kiel. Na verdade, Jehring não queria ir para Giessen: ele tinha exigências financeiras tão altas que, depois que tais foram aceitas, nada lhe restou a não ser aceitar a nomeação. Ele permaneceu 17 anos em Giessen. Instalou-se ali confortavelmente. Habitou três casas, sendo a primeira delas na rua que mais tarde veio a receber seu nome. Por fim, ele morou em uma vivenda, à qual pertenciam quatro jeiras de terra e 200 árvores frutiferas, no meio do verde, na atual Frankfurter Strasse, naquele tempo com vista sobre o vale do Lahn. Ao tempo em que veio para Giessen, ele havia cas ado pela segunda vez, após a dolorosa morte de sua primeira esposa. Deste segundo casamento resultaram 5 filhos, dos quais 4 nasceram em Giessen.

Jhering era um homem multiplamente ocupado: ele dava aulas, trabalhava intensamente em suas obras científicas, cultivava a vida familiar e, além disso, a vida social. Convidava para noites de música de câmara com artistas de renome, sendo que ele próprio atuava como pianista. Na casa de Jhering, como conta o filho Hermann, "a vida social, sem cerimônias, era um costume; o quarto de hóspedes raramente ficava vazio por muito tempo."

Frente a tais descrições, impõe-se a pergunta de como os docentes do século XIX conseguiam fazer tudo isso: eles tinham seu programa acadêmico, examinavam as provas, faziam pareceres, compunham - no caso de Jhering - uma enorme obra científica; não havia computador, nem assistentes, nem secretária e não havia financiamento por meio de terceiros (também não eram necessários). Não obstante, atingiram feitos grandiosos, ao mesmo tempo em que se passeava, fazia-se música, cultivavam-se morangos e aspargos, criavam-se pombos e frangos, jogava-se carta com os amigos uma vez por semana. Freqüentava-se a „Sonderbund", uma associação de professores, a qual servia igualmente à troca de idéias e ao prazer comum pelo vinho e pela cerveja; cultivava-se contatos com as ciências naturais da mesma forma que com a prática jurídica - e nós ficamos admirados face a tal fenômeno.

Em Giessen, Jhering fundou as bases de sua extraordinária reputação: „.. . . aqui, permitome dizer, fiz meu nome por meio dos volumes do „Geiste des Römischen Rechts” [Espírito do Direito Romano], ao que se somam ainda alguns trabalhos menores e a organizacão de uma revista." $\mathrm{O}$ termo revista, refere-se aos "Jahrbücher für die Dogmatik des heutigen römischen und deutschen Privatrechts" [Anuários sobre a Dogmática do atual Direito Privado Romano e Alemão], ou "Jherings Jahrbücher" [Anuários de Jhering], editados primeiramente em cooperação com Gerber, e, após, individualmente.

Sobre a grande obra „Der Geist des römischen Rechis auf den verschiedenen Stufen seiner Enturicklung" [O espírito do Direito Romano nas diferentes etapas de sua evolução] haveria muito a dizer. Essa coleção de numerosos volumes constituiu a primeira de suas grandes tentativas de afirmar o Direito - ante as florescentes ciências naturais, bem como a ameaçadora ramificação do Direito por meio da legislação nacional - como ciência e de fazer referência a princípios gerais. Jhering dedicou-se a tal obra tanto quanto Cézanne ao Mont St. Victoire. Enquanto sua conclusão se delongava, o autor sofria continuamente com os exigentes editores, os quais devolviam os capítulos, mais criticados do que apreciados, impedindo-o de se desembaraçar do projeto. O livro precisava ser terminado, "para que não se denotasse que eu teria, ainda em vida, desistido do Espirito (Geist)".

Sobre as idéias inseridas nesse então ainda inacabado, Geist', poder-se-ia discorrer longamente; porém, gostaria mais de cingir-me a uma única idéia jurídica, a qual Jhering desenvolveu em um pequeno artigo, e com a qual fez história no Direito.

Refiro-me à frutífera descoberta de um novo fundamento de pretensão, hoje essencial, a saber, a culpa in contrahendo. Em um trabalho homônimo, publicado em 1861, Jhering buscou a solução de casos que apresentavam as mesmas seguintes estruturas: viciada a conclusão de um contrato, este é ineficaz, e uma das partes resta prejudicada. Por exemplo: 
alguém encomenda 100 libras de uma mercadoria, e o sistema métrico é confundido com o dos quilos. A mercadoria é entregue, mas devolvida pelo comprador em razão da quantidade inadequada. Conforme a teoria vigente do erro essencial, era o contrato ineficaz, de forma que nele não se poderia fundamentar pretensão, mas „quem”, peguntou Jhering , arca com os custos das embalagens usadas e da postagem"? Ou então: X, em Colônia, delega ao banco Z, em Frankfurt, via telegrama, a venda de determinados títulos de fundos públicos em seu nome. Porém, ocorre erro quando da expedição do telegrama, de modo que ao banco chega uma ordem de compra dos títulos, a qual se executa. Logo em seguida, cai a cotação dos títulos, e X é gravemente prejudicado. Quem arca com os prejuízos?

Jhering, quanto a casos dessa espécie, encontra na doutrina apenas opiniões individuais, sem tese coerente, ou mesmo pura omissão, preponderantemente. Ele busca e encontra um novo princípio de Direito, mas não sem antes ter interrogado exaustivamente o Direito tradicional. Situamo-nos em uma época em que o Direrito Civil ainda era dominado pelo princípio da ação do Direito Romano: as pretensões materias ainda se viam aprisionadas pelas fórmulas de ação específicas (actiones), das quais se dispunha apenas número e tipo limitados. Mas nem mesmo essas ações se aplicavam aos referidos casos. Com base no contrato (actio emtz), não podia o prejudicado mover pretensão, pois nenhum contrato chegou a existir. A actio doli exigiria dolo do agente, mas nos citados casos tratava-se antes de negligência, ou seja, no máximo, de culpa. Exclui-se a actio legis Aquiliae, porque não se interviu na propriedade da coisa, cuidando-se sempre de meros danos materiais. Um princípio geral de Direito que vedasse o dano culposo à coisa de outrem inexistia à época, bem como hoje, no Direito alemão.

Era necessário demonstrar, então, para se fundamentar uma pretensão de indenização material, além dos elementos prejuízo e responsabilidade, um terceiro e específico elemento, isto é, a conexão da responsabilidade com uma relação contratual. Partindo do pressuposto de que um contrato de compra-e-venda fundamenta não apenas a pretensão de execução, como também pode ensejar pretensão de indenização, Jhering desenvolveu a possibilidade de cindir-se a ineficácia do contrato: é possivel que o contrato seja ineficaz quanto à pretensão de cumprimento, mas, apesar disso, enseje outras pretensões, como a própria pretensão de indenização, que também poderiam surgir caso o objetivo principal do contrato - o adimplemento - não fosse possivel.

Compreendem-se, além da obrigação de cumprimento, deveres de um tipo próprio que estão implícitos no curso da conclusão do contrato. Jhering fala da necessária diligência das partes ao contratar. A desatenção dela configura a culpa in contrahendo, isto é, a culpa quando da conclusão do contrato, que enseja uma pretensão de indenização para a parte prejudicada. Jhering persegue esse pensamento por meio de todas as formas de relações contratuais falhas, pensáveis à época. Não sem orgulho apercebeu-se de ter formulado um novo princípio de Direito.

Muito mais da perspicácia de nosso astro de Giessen poderia ser referido, como a diferenciação entre interesse positivo e negativo, que ele desenvolveu em conexão com os seus casos, entre muitos outros exemplos... Mas para isso deveriam-se mencionar outras idéias jurídicas.
Quanto à ascensão da culpa in contrahendo, gostaria apenas de trazer, ainda, à lembrança que o Bürgerliches Gesetzbuch (BGB), de 1896, acreditava prescindir de tal figura jurídica e adotava apenas poucos grupos de casos. Desse desprezo, vingou-se a culpa in contrahendo de forma rápida e efetiva: já em 1911 adveio o famoso precedente dos Rolos de Tapete do Tribunal do Reich, no qual o princípio de Jhering encontrou aplicação. Por meio da cláusul geral de Treu und Glauben [Confrança], a culpa in contrahendo teve acesso a todos os ramos do Direito Civil, sendo seu âmbito de aplicação cada vez mais ampliado, de forma a ser incorporada a todas as teorias gerais de responsabilidade com base na confiança e, hoje, cobrada em qualquer exame de Direito Civil. Tardiamente, sentiu-se o legislador à vontade para ao menos mencioná-la, apenas em 1977, na lei sobre termos e condições gerais dos negócios, sob o título "descumprimento de deveres quando das negociações contratuais". Somente com a modernização do Direito Obrigacional de 2002, buscou-se uma regulação positivada do instituto: cerca de 150 anos após, encontramos cristalizada em parágrafos a percepção de Jhering de que, em uma relação obrigacional, contêm-se, não apenas deveres de prestação, mas também deveres de cuidado, que podem surgir independentemente da obrigatoriedade da prestação (veja-se o $\$ 241$, Abs.2, BGB). Então, quando vós, caros senhoras e senhores, passeardes por Gießen, tenheis em mente: aqui, além do extrato de carne de Liebig, descobriuse a culpa in contrahendo.

\section{III.}

Mudança de cenário. Em junho de 1875, envia-se uma convocação a um bávaro docente em Berna, chamado Carl Gareis. Ele, de 31 anos, aparenta já ter esperado escapar da vida universitária suíça, como ele próprio escreveu. "Os professores alemães passam por trếs estágios na Suiça: primeiramente, vêem-se encantados, empolgados, animados com a natureza a a liberdade; depois, tornam-se, de súbito, profundamente infelizes... até que começa o terceiro estagio, aquele da apatia, da indiferença e da introspeç̧ão". Gareis nem precisou acompanhar o segundo estágio, pois dois anos após o começo de sua docência em Berna já recebeu os convites para Greifswald e Gießen, vindo aceitar o último.

Consoante alguns testemunhos, ele sentiu-se muito bem em Gießen, a começar pela aceitação no círculo de colegas, que foi, "em todos os sentidos, muito cordial e prazerosa no mais alto grau", "os membros da Faculdade de Direito mostravam-se continuamente bons e amigáneis uns com os outros e assim também comigo."

Também a paisagem do norte de Hessen, pela qual ele, não raramente passeava, por ocasião de sua presença em reuniões da faculdade. De um modo geral, sua muito aconchegante "Atenas do Lahn" haviam lhe agradado de imediato. Lá, era como se, assim ele descreve, "em todas as suas ruelas e ruelinhas pairasse um suave, morno e moreno claro aroma de café com leite". Tudo isso não o impediu de mudar-se em direção a Königsberg treze anos depois. A sua última estação, todavia, foi Munique, onde ele morreu, em 1923, na condição de ilustrússimo emérito.

Mas foi em Gießen que Gareis lançou as fundações de sua obra científica em geral, e desenvolveu idéias jurídicas evolucionárias. Antes de me referir a elas, farei algumas observações gerais sobre suas atividades em Gießen. É sempre bom para uma faculdade poder chamar de seus, além de acadêmicos aplicados e competentes, algumas personalidades inquietas e que 
trazem um pouco de movimento. A esse tipo pertencia Gareis. As áreas em que ele, literalmente, se embrenhava, estendem-se por quase toda a ciência do direito: ele, o civilista, escreveu um livro sobre "Direito do Estado do Grão-Ducado de Hessen", um livro sobre Estado e igreja na Suiça, uma obra sobre "Instituiçoes do Direito Internacional Público", um livro sobre "Direito Colonial Alemão", isso apenas para mencionar algumas de suas obras não-civilistas. Certamente, ele não foi apenas um professor de Direito e um autor jurídico. Desde poucos anos de sua chegada, o vemos como diretor de ações arqueológicas e como co-fundador da "Associação do Norte de Hessen para a História Local" (mais tarde, chamada de "Associação do Norte de Hessen para a História'). Pressionado por amigos, ele deixou-se apresentar como candidato do distrito eleitoral de Alsfeld-Lauterbach-Schotten nas eleições de 1878. Seu oponente foi o Conde de Solms-Laubach, a quem ele venceu por grande maioria

Nesse contexto, ocorrem-me, sobretudo, duas coisas. Em primeiro lugar, depois que Gareis chegara a Berlim na condição de distinto deputado, ele ingressou em um grupo político (o dos nacional-liberais), tendo transitado, no entanto, entre membros de outros partidos com muito prazer. E, ademais, a atividade parlamentar, aqui eu cito, "não me impedin de forma alguma de cumprir com meus deveres de ensino: eu podia dar todas as minhas aulas; naturalmente. nem sempre no borário regular... mas eu sempre recuperei aulas canceladas".

Logo que voltou de Berlim, Gareis precisou fazer, em 1883, urna dificil escolha entre ir a Marburg e permanecer em Gießen, para aqui tomar-se chanceler da universidade. Ele se decidiu pela segunda opção.

Eu não teria contado tanto dessa vida, se ela não tivesse sido vivida por um jurista importante. As idéias que Gareis trouxe ao Direito, na época em que viveu em Gießen, situam-se no centro do Direito Civil. Trata-se da questão central acerca dos bens jurídicos que a Ordem Jurídica do Direito Civil reconhece como dignos de tutela, e da forma pela qual essa tutela de bens funciona No que pertine à essa questão, o Direito Civil das últimas décadas do Século XIX estava em profunda revolução, pois o mundo modemo, com suas transformações econômicas e técnicas, criou necessidades de tutela juńdica estranhas ao Direito Comum tradicional

A questão havia começado com a contenda acerca da reprodução de livros, que se intensificava a partir de $1770 \mathrm{na}$ Alemanha, atravessando o século XIX. Primeiramente, a controvérsia foi essencialmente debatida no âmbito do conceito de propriedade (propriedade intelectual). Finalmente, foi descoberto um Direito sui generis, o Direito de Autor. Rapidamente, tomou-se visível que a posição jurídica dos autores e dos editores não era o único progresso da civilização que perturbava a estrutura do Direito Comum. Através do invento da fotografia foram colocados em risco também os interesses de artistas plásticos. Os avanços técnicos exigiam uma proteção para inventos, enquanto a formação de áreas econômicas supra-regionais exigia uma tutela para protótipos, modelos e marcas. $\mathrm{O}$ desenvolvimento social também fez com que direitos de personalidade, no sentido hoje dado a eles, ganhassem destaque: o direito ao nome e, novamente em conexão com a fotografia, o direito à própria imagem.

Os civilistas do século XIX ignoravam, em certa medida, esses novos fenômenos, pois integrá-los ao sistema tradicional do Direito Comum traria evidentes dificuldades. Isso se devia ao fato de que o Direito romano colocava a propriedade no centro da teoria dos bens jurídicos, sendo reconhecidas, como objetos da propriedade, somente as coisas, compreendidas hoje como objetos corpóreos. Portanto, a contenda acerca da reprodução, nessa primeira fase, era essencialmente abordada com o auxilio do conceito de propriedade, por duas posições divergentes. Os apoiadores da livre reprodução de livros diziam: "quando eu compro um livro e adquiro dele a propriedade, eu posso dispor dele ao meu bel-prazer; assim, eu posso também reproduzir o texto". Os autores e os editores diziam, em contrapartida: "desde o princítio, o livro é vendido e alienado pelos proprietários originais (o autor e os editores autorizados) com a restrição de que ele pode ser lido, revendido e mesmo destruído, mas não reproduzido".

A solução devia se direcionar a uma das seguintes opções: ou a criação intelectual como tal (independente dos exemplares individuais do livro) ascende à posição de objeto da propriedade (essa idéia já havia desenvolvido com plena clareza o filósofo Johann Gottlieb), ou seja inventada uma nova categoria de direitos. De qualquer forma, o sistema do Direito Comum devia ser aberto.

E agora nos aproximamos de nosso colega de Giessen. Entre os professores de Direito da época, que, ao contrário da maior parte de seus pares, não rejeitaram o mundo moderno, mas sim se lançaram em sua direção, distinguem-se dois nomes: Josef Kohler, o formidável autor de Berlin, e Carl Gareis. Quando este último tomou para si o problema, sobretudo através do artigo sobre "A esséncia jurídica do Direito de Autor, bem como da Tutela de Firmas e Marcas" (de 1877), muito já havia ocorrido no campo da legislação: havia lei imperial sobre o direito do autor a obras escritas, imagens, composições musicais, peças dramáticas, bem como sobre obras de artistas plásticos; lei imperial acerca do Direito de Autor sobre protótipos e modelos; tutela legal de fotografias; isso sem falar nas muitas leis estaduais existentes.

No entanto, não havia uma teoria unificadora que pudesse explicar as manifestacões dos novos direitos através de um único princípio. O conceito de propriedade desintegravase segundo as concepções daquele tempo. Gareis atribuiu então, aqui posso, ainda, referir-me às pesquisas de Diethelm Kippel, também de Gießen, a todas as referidas posições jurídicas fundamento comum, externo à propriedade. De fato, fundamentou-as no direito da personalidade. A categoria do direito da personalidade (ou dos direitos de personalidade) não foi inventada por Gareis; ela pairava, com conteúdos mutáveis, já há um longo tempo através dos "direitos naturais", já tendo, carregada dessa pluralidade, chegado à beira da doutrina do Direito Comum.

Gareis partiu do direito fundamental do sujeito de dispor de suas próprias faculdades e de demandar pelo resultado através delas obtido, enquanto terceiros seriam obrigados a "não obstaculizar", a "não interferir" com essas transações. Esse pensamento culminou na seguinte fórmula: o sujeito de direito tem o direito de ver reconhecida sua individualidade como tal. Deve ser adicionado que Gareis, para controlar uma eventual ausência de limites, envolveu inteiramente o Direito positivo nessa concretização. Trata-se de relações jurídicas que existem "dentro do Direito positivo"; a individualidade não é reconhecida e tutelada como tal pelo Direito em toda e qualquer relação. Gareis vincula a positividade da tutela legal com uma idéia jurídica sobre-positiva.

Nessa idéia ele pode acomodar tudo que não pertence ao mundo das coisas da propriedade: o direito à conservação da própria existência, o direito à honra e ao nome, assim 
como o direito autoral, o direito do inventor e a proteção do modelo e desenho comercial. A propriedade como o domínio jurídico sobre a coisa recebe um equivalente, mais especificamente, o domínio jurídico sobre a individualidade de uma pessoa, para qual um nome ainda tinha que ser concebido. Gareis fala de direitos individuais, já que os direitos da personalidade são-lhe extremamente ambíguos ${ }^{1}$.

Essa terminologia provou não ter, entretanto, um futuro promissor, visto que posteriormente Gareis fala altemativamente tanto de direito individuais, como de direitos de personalidade ${ }^{2}$. Permanece, contudo, a idéia de contrapor à propriedade um tipo diferente de mundo das coisas, onde o domínio da vontade relaciona-se não a objetos corpóreos, mas sim a assuntos intelectuais ou pessoais. A doutrina desse professor de Giessen marca o início da moderna doutrina do direito das coisas, que, sem dúvida, logo a seguir continuou avançando e separou os chamados direitos das coisas imateriais dos direitos da personalidade em sentido estrito. Se isso representaria um avanço no conhecimento, seria discutível. Deixase contestar o fato de que o direito à esfera privada, o mais nobre de todos os direitos da personalidade, apresenta-se quase tão negociável quanto o direito de exploração de um escritor.

\section{IV.}

Chegou o tempo de passar ao Direito Penal. Em Giessen, atuaram famosos penalistas, como Franz von Liszt entre o ano 1879 até o de 1882, quando publicou a primeira edição de seu famoso manual de Direito Penal (1881). Além disso, atuaram em Giessen Reinhard Frank, depois seu sucessor Ernst Beling, esse último, entretanto, apenas como professor visitante por dois anos (1900-1902). Este último, antes de partir para Tübingen, muito elogiou a Universidade de Giessen e seu "espirito jovem". Lecionaram também em Giessen Wolfgang Mittermaier, depois como jovem docente Karl Engisch, cujas aulas de Filosofia do Direito pude ainda assistir em 1954 em Munique ${ }^{3}$.

Entre todos os penalistas, eu escolho Reinhard Frank, por dois motivos: ele deixou uma detalhada autobiografia ${ }^{4}$ e porque seu tempo em Giessen remete a idéias que tiveram duradouros efeitos posteriores. Frank era de Hessen, nascido em 1860 em Reddinghausen, e era originário de uma família de industriários. Mais precisamente, seu avô, por parte de pai, foi pastor, mas não se entendeu com os órgãos religiosos e sem rodeios comprou uma forja e viveu a partir daquele momento como produtor de ferro. Isso determinou o destino do nosso penalista de uma maneira especial, e como ele mesmo se expressa: "o homem é mais

Das junstische Wesen der Autortechte ("A essência juríica dos direitos de autor") (Fn. 53) p. 199

KLIPPEL, Die Theorie der Persönlichkeitsrechte "A A teoria dos direitos da personalidade") (Fin. 58) p. 227

Engisch - então Professor na Ludwig-Maximilians-Universität München - escrevell em um tempo no qual a Faculdade de Direito de Giessen ainda não tunha sido fundada, un artigo muito elucidativo denominado „Os juristas de Giessen dos últimos 100 anos" em Ludwigs-Universität - Justus Leebig-Hoclschule 1607 - 1957, Festschnift zur 350-Jahrfeere, Giessen1 1957, P. 17 ff. Para a história do Direito Penal na Universidade de Gessen, veja Walter Gropp, Vestigia Iuris Criminalis, em: Rechtswissenschaft im Wandel (Fn. 7) p. 23 ss.

Ela se encontra em: Hans Planitz (Hg), Die Rechtswissenschaft der Gegenwart in Selbstdarstellungen, Parte III, Leipzig 1929, p.1 ss. possuido por solo e terra do que os possu'"s. Já nessas frases sugere-se seu dom para a sucinta e exata formulação. O pai de Reinhard Frank continuou então a conduzir a forja, enquanto seu filho dedicou-se à jurisprudência.

Quando tinha 29 anos e já estava direcionando-se a uma carreira acadêmica, pouco tempo antes de sua nomeação como professor em Giessen, seu pai morreu de maneira inesperada. Reinhard Frank sentiu-se então pressionado, apesar de seus interesses acadêmicos, a assumir a forja, "ali estava presente o suor do meu pai". Então ele conduziu lá os trabalhos durante seus nove anos em Giessen (1890-1899) e com isso, levou uma vida dupla como empreendedor e como Professor de Direito. Isso talvez explique a orientação prática dos seus interesses científicos. Ele escreve sobre isso: "Desse modo, eu muito vi e aprendi, o que normalmente é estranho a um acadêmico. Particularmente, eu reconheci que a direşão de um negócio de médio porte no mínimo exige o mesmo nivel de inteligência que a carreira de professor, além disso, exige o dobro de energia"."

Frank inicialmente começou a faculdade de Filologia em Marburg, após um semestre, contudo, transferiu-se para o Direito, com a concordância de seu pai, que, como o filho expressa, pensava que "um jurista não se corromperia a um homem de negócios como um filólogo". $\mathrm{O}$ estudo do Direito direcionou Frank para Munique e para Kiel. Quando da prática obrigatória (Referendariat), retornou para Marburg, onde elaborou seu doutorado sobre o Direito Penal natural de Regnerus Engelhard, aluno de Christian Wolff. Com uma versão ampliada desse trabalho, habilitou-se ao cargo de professor?. Não era raro que faculdades, que tinham consciência de seu valor e confiança em si mesmas, deixassem valer dissertações como habilitações, não obrigando, desse modo, jovens talentos a escreverem um segundo grande livro. Frank escolhera a combinação das disciplinas de Direito Penal e de Processo Civil e foi chamado para uma dessas cátedras em Giessen em maio de 1890. Logo ele também casara.

Nessa cátedra, ele realizou em apenas alguns anos os trabalhos que fizeram dele um dos mais representativos penalistas alemães, entre eles, os conhecidos Comentários ao Código Penal do Reich, onde gostaria de me demorar alguns minutos. Os Comentários de Frank não foram os primeiros. Tinham, entretanto um formato próprio: eles excediam os difundidos manuais, sem, contudo, representarem um volume indigesto aos estudantes. Os Comentários foram inicialmente pensados para o estudo do Direito nas faculdades. Com o tempo, tornaramse, entretanto, uma obra de ponta, que os próprios tribunais continuamente consultavam. A primeira edição da obra foi publicada em 1897 , trinta anos depois, pode o orgulhoso autor trazer a $17^{\mathrm{a}}$ edição, que totalizou entre 37 a 42 milhares exemplares. ${ }^{10}$

Os Comentários tornatam-se famosos não apenas pela sua conexão entre os níveis acadêmico e prático, mas também pela capacidade de Frank de moldar as conhecidas regras e definições em formulações curtas, precisas e fáceis de lembrar. Trata-se das famosas fórmulas

"Autcbiografia (Fn. 64), P. 2

"Autobiografia (Fn.64), p. 19

${ }^{7}$ Autobiografia (Fn.64), p. 20

${ }^{8}$ Autobiografia (Fin.64), P. 8

'Remhard Frank, Des Regnerus Engelhard peinliches Recht. Ein Beitrag zur Kenntrnis und Beurteihung der Wolff' schen Rechtsphilosophie. Marburger Inauguraldissettation, 1887

Autobiografia (Fn. 64), p 24. Os Comentários foram publicados pela editora T.C.B.Mohr em Tübingen 
de Frank, que quando estudante tive que estudar e que, como me convenci, estão ainda presentes nos manuais.

Elas aparecem já na primeira edição dos Comentários. A título de exemplo, cite-se a famosa Fórmula de Frank para a distinção entre a desistência da tentativa, voluntária e involuntária. "Voluntária é então a desistência..., quando o agente diz para si mesmo: eu não quero continuar a agir, mesmo se eu o pudesse. Involuntária é, quando o agente dizpara si mesmo: eu não posso mais agir, mesmo se eu o pudesse" 1 . Há também a Fórmula de Frank para a distinção do dolo eventual (dolus eventualis) e da imprudência consciente: o dolo eventual apresenta-se como uma relação singular mental, quando o agente diz para si mesmo: "poderá ser assim ou diferente disso, eu agirei de qualquer jeito". "Se o agente diz por outro lado: se eu soubesse, que seria assim, teria deixado de agir, não há mais dolo eventual e, no máximo, poder-se-ia falar de imprudência".2.

Os Comentários inteiros são impregnados dessas fórmulas de fácil memorização. E importante notar, que nelas está incorporada a doutrina, elas não são apenas simples regras gerais, mas sim uma síntese de todo um conhecimento científico.

Com esses Comentários, traçou-se para Frank uma brilhante carreira (apesar do encargo da forja). Quando ele foi para Halle no ano de 1899, ganhou do diretónio de estudantes de Giessen uma festa de despedida, na qual ele prometeu que iria se lembrar sempre agradecido dessa homenagem ${ }^{13}$. O caminho, então, o guiou através de Tübingen para Munique. Na sua biografia, ele salienta principalmente sua nomeação para trabalhar em um projeto para um novo Código Penal Alemão. Nesse contexto, ele deixa reconhecer uma certa fadiga em relação ao ensino universitário: "O ensino na cátedra me parece apenas orientado para a obtencão de méritos nos exames, a prova para ambas as partes [professores e alunos] de uma qualidade indigna". ${ }^{14}$

Embora ainda devêssemos aludir a grandiosas idéias jurídicas concebidas, formuladas e publicadas em Giessen, o curto tempo exige que eu conduza minha preleção ao seu final. Gostaria de referir ainda um jurista que, há mais de oitenta anos, escreveu um livro em Giessen, o qual ainda hoje se estuda e se debate. Refiro-me a Leo Rosenberg e à sua obra acerca do Direito Processual Civil, em que se contêm muitas idéias jurídicas.

Na época em que Rosenberg veio a Giessen, em 1912 - com 33 anos de idade, proveniente da Silésia -, ele já havia escrito dois livros, que ainda hoje encantam os especialistas e são amplamente consultados: sua dissertação sobre "O ônus da prova segundo a ordem jurídica processual civil e o Código Civil' (Die Beweislast nach der Zivilprozessordnung und dem Bürgerlichen Gesetzbuche) e a sua habilitação em Göttingen sobre "A representação no processo" (Die Stellvertretung im Prozess), cuja versão impressa superou as mil páginas, fato nada comum à época.

\footnotetext{
${ }^{11} 1^{2}$ Ediç̃o, $\$ 46$ Anm. II

Autobiografia (Fn. 64), p. 20
}

Já a tese de doutorado foi um sucesso extraordinário. $O$ interesse de Rosenberg pelo tema foi despertado por um concurso da Faculdade de Breslau enquanto ele ainda era estudante: "...no meu terceiro semestre eu ainda não estava suficientemente maduro para o trabalho, ainda não haria cursado Processo Cinil, mas fui, no entanto, levado pelo tema, com o qual me mantive ocupado durante os semestres subseqüentes e sobre o qual conclui meu doutorado em Breslau em 1900"assim relata Rosenberg, pessoalmente, que acabou por transmitir seu tema ao seu discípulo Eduard Bötticher, igualmente professor em Giessen. O mérito da dissertação deve ser tanto mais elevado quando se toma em consideração que, à época de sua realização, o BGB (Código Civil Alemão) ainda nem sequer havia entrado em vigor, e estava para ser introduzido em caráter pioneiro. É impressionante: o trabalho surgido em 1900 foi publicado em $1965 \mathrm{em}$ quinta edição, não como raridade histórico-jurídica, mas como obra jurídica atual.

Rosenberg veio a Giessen com excelentes pré-trabalhos processuais, onde atuou durante 20 anos como professor e pesquisador junto à Faculdade local. A cátedra que ele ocupou era talhada, em virtude da proximidade prevalente entre o Direito Civil e o Direito Processual existente em Giessen, especialmente para ele, de modo que Bötticher remete a uma "Escola Giesseniana", cuja característica principal é a ligação entre essas duas especialidades do Direito.

Depois do que se referiu, não impressiona que o dedicado e produtivo Rosenberg, após certo tempo de exitosa cátedra, tenha se lançado à elaboração de um novo, "atual", como ele refere, manual de Processo Civil, para o qual ele identificou uma vivaz necessidade, sobretudo entre os estudantes. Ele devia ser mais que um compêndio, mas ao mesmo tempo não tão longo quando os manuais até então disponíveis. $O$ desígnio de Rosenberg pode ser melhor percebido quando se permite que ele mesmo o explane: "Todo entendido perceberá prontamente que meu livro diferencia-se em arranjo e estrutura dos demais manuais de Direito Processual Civil até então existentes. Em abrangência, mas, tomara, não em conteúdo, fica ele atrás dos demais. Isso se conseguiu através de uma rígida sistemática, de uma perspicaz elaboração dos princípios fundamentais do Direito Processual Civil, de uma bem acabada definição de conceitos e concisão expressiva.. A sistemática do livro fixa-se sobre preceitos da lógica e do contexto interno..." $\mathrm{O}$ autor esperava que o livro fosse encontrado principalmente nas mãos de estudantes, mas também de referendários (Referendare), juízes e advogados - e assim ocorreu sempre a partir da primeira edição.

Em relação às novas idéias, que o livro contém e propaga, vali-me da ajuda de biógrafos especializados. O seu discípulo Karl-Heinz Schwab aponta, dentre as inovações, a teoria da coisa litigiosa e a descoberta da pretensão processual como pretensão de tipo especial, bem como a teoria dos atos processuais e a doutrina da coisa julgada, que, a partir da primeira edição do manual, corresponde à coisa julgada processual. Rosenberg, assim me parece, assentou as fundações para a autonomia do pensamento jurídico processual diferenciando-o do direito material. Pode-se afirmar: Rosenberg levou a cabo a superação do sistema de ações romano.

A primeira edição do livro apareceu em 1927, ano em que Rosenberg era Reitor da Universidade de Giessen. Reelaborações ocorreram em 1929 e 1931. Após a guerra, o livro teve, até os dias de hoje, um grande número de novas edições. Apesar do encargo da reelaboração ter passado posteriormente aos seus discipulos universitários, ele ainda é "o Rosenberg". 
O jurista sentia-se bastante bem em Giessen, prova disso são os longos anos de permanência na cidade à beira do Lahn. Convites de Bonn e Greifswald foram recusados. Em 1932, entretanto, Rosenberg aceitou um convite de Leipzig, onde ele acabou por experimentar um término provisório de sua carreira: devido à sua origem judaica ele for aposentado, de modo forçado, em 1934, com 55 anos de idade. Mais tarde foi-lhe cassada a pensão. Felizmente pôde ele sobreviver ao domínio nazista em uma casa de férias de sua esposa no Allgäu, de modo a, depois da guerra, poder assumir o posto de professor na Universidade de Munique. Aos 67 anos de idade, foi designado para a Universidade de Munique e, aos 72 anos de idade, novamente nomeado funcionário público vitalício. Seu manual, atualizou-o ele mesmo até a nona edição, de 1961, época em que estava com 82 anos de idade. Dois anos depois veio a falecer. Não se podem avaliar as contribuições do jurista que nos poderiam ter sido transmitidas não tivesse tomado lugar a sua pausa forçada.

Giessen, entretanto, onde ele passou os melhores anos de sua vida, segundo seu próprio juízo, pode orgulhar-se de ser o berço do mais famoso manual de Direito Processual alemão, com influências no mundo todo, do qual o Direito Processual alemão alcança extraordinário prestígio. A Universidade de Giessen nomeou seu ex-Professor e Reitor Conselheiro Honorário, de modo a preservar, em alto patamar, a memória desse homem, assim como a de todas as suas grandes personalidades universitárias.

\section{VI.}

Esse relato encerra por hoje as idéias jurídicas provenientes de Giessen. Muitos perguntarão: onde estão as idéias formadas após a reabertura da Universidade? Depois da Segunda Guerra não foi lançada ao mundo nenhuma outra idéia jurídica proveniente de Giessen? Com razão, assim o perguntam. A refundação da Faculdade de Direito em Giessen, como ela se chama atualmente, pertence à gama das afortunadas incursões da políticà de Hessen. Eu devo a essa reabertura sete exitosos e proveitosos anos como jovem professor em meio às movimentações políticas de 1968.

A arrojada decisão de reabrir uma outra Universidade 20 quilômetros ao sul de Marburg valeu a pena já em 1962, assim como ocoreu com a fundação em 1607. Hoje, como no passado, brilham as conquistas intelectuais, a invenção de novas regras, a criação de contextos, a lapidação de conceitos, o estabelecimento de novas construções jurídicas e o intercâmbio de refinados argumentos. Para falar-se sobre as conquistas jurídicas ocorridas no passado próximo e na atualidade, falta uma distância histórica. Assim, eu peço clemência àqueles que hoje trabalham na área jurídica em Giessen, e também a todos os ex-Giessenianos ainda vivos, pois os seus nomes e as suas idéias faltam à minha preleção. A essas personalidades peço paciência até o próximo jubileu da Universidade Justus-Liebig.

A Faculdade de Direito, entretanto, que depois de épocas sombrias novamente estabeleceu-se e notavelmente desenvolve-se, desejo esplendor e prosperidade e também um vivo e venturoso futuro.
Das System des deutschen bürgerlichen Rechts ${ }^{1}$

\section{Prof. Dr. Jan Schapp, Gießen}

\section{Problemstellung}

Von System des Rechts sprechen wir im Hinblick auf die Ordnung, unter der wir eine Vielfalt juristisch bedeutsamer Erscheinungen erfassen können. Diese Ordnung ist nicht von mathematischer Struktur wie etwa die Abfolge von Zahlen in der Arithmetik oder wie die Körper der Geometrie. Es handelt sich vielmehr bei dieser Ordnung um Sinnzusammenhänge, für die im Laufe der Entwicklung des Rechtes das Verständnis gewachsen ist. Der Begriff des Systems ist schon erfullt, wenn sich eine Vielfalt von Erscheinungen unter dem Aspekt einer solchen Ordnung in einen Zusammenhang bringen lassen. Die Bedeutung der Ordnung liegt darin, daß sie wohl überhaupt erst die Lehre des Rechtes ermöglicht, und auf diesem Wege dann auch die Rechtsfindung im Einzelfall zumindest erleichtert. Wir wollen nun allerdings hier nicht abstrakt den Begriff eines Systems des Rechts weiter zu konkretisieren versuchen, sondern sofort mit der Darstellung des Systems des bürgerlichen Rechts beginnen und damit gewissermaßen in der Welt der Erscheinungen dem Systembegriff selbst weitere Kontur verleihen.

Entscheidend für unseren Zugang zum Recht scheint uns nun das Gebilde des juristischen Falles zu sein. Wir sind gewohnt, die Entscheidung des Richters auf den Fall zu beziehen, der ihm von den Parteien zur Lösung und Entscheidung vorgetragen wird. Damit scheint der Begriff des Falles seine Bedeutung in dem Gebiet der Rechtsanwendung durch den Richter zu haben. Der Richter könnte in einem kodifizierten Recht allerdings den Fall gar nicht entscheiden, wenn nicht schon das von ihm anzuwendende Gesetz sich auf den Fall - in welcher Weise auch immer - beziehen würde. Das dürfte eine der wesentlichen Erkenntnisse der von Philipp Heck zu Beginn des 20. Jahrhunderts entwickelten Interessenjurisprudenz gewesen sein. Die Interessenjurisprudenz spricht allerdings nich vom Fall, sondern vom Konflikt, den das Gesetz entschieden hat. Der Richter hat diese Konfliktsentscheidung des Gesetzes in bezug auf den ihm vorgelegten Fall denkend nachzuvollziehen. Beide, Gesetzgeber und Richter, sind damit also im Grunde auf denselben Fall bezogen. Ich habe diesen Ansatz in den Mittelpunkt meiner Betrachtung der juristischen Methodenlehre in meiner 1983 erschienenen Schrift "Hauptprobleme der juristischen Methodenlehre" gestellt, die 1985 unter dem Titel "Problemas fundamentais da metodologia jurídica" in portugiesischer Übersetzung in Porto Alegre erschienen ist. Meine 1998 erschienene Schrift "Methodenlehre des Zivilrechts" stellt dann eine weitere Ausführung dieses Ansatzes dar. Auch diese Schrift ist unter dem Titel "Metodologia do direito civil" 